\title{
Lung Ultrasound B-lines as a Surrogate Marker for High Left Ventricular Diastolic Pressures; a bed-side Diagnostic tool
}

Alsayed Ali Abdou Almarghany ${ }^{1}$, Moaz Atef Elshahat Abdel ${ }^{2}$ ati and Abdulaziz Aboshahba ${ }^{2 *}$

${ }^{1}$ Cardiology Department, Alazhar University hospitals, Cairo, 11675, Egypt

${ }^{2}$ Pulmonology Department, Alazhar University hospitals, Cairo, 11675, Egypt

*Corresponding Author: Abdulaziz Aboshahba, Cardiology department, Faculty of Medicine, Alazhar University, Cairo. Egypt.

Received Date: August 27, 2021; Accepted Date: September 15, 2021; Published Date: September 21, 2021

Citation: Natalia L. Mercado., Mariano Rubio., Martín Cisneros., Santiago Trejo; Maximiliano Giraudo. (2021) Lung Ultrasound B-lines as a Surrogate marker for high Left Ventricular Diastolic Pressures; a bed-side Diagnostic tool. J. Clinical Cardiology and Cardiovascular Interventions, 4(18); DOI:10.31579/2641-0419/217

Copyright: ( $\odot 2021$ Abdulaziz Aboshahba, This is an open-access article distributed under the terms of the Creative Commons Attribution License, which permits unrestricted use, distribution, and reproduction in any medium, provided the original author and source are credited.

Graphical abstract
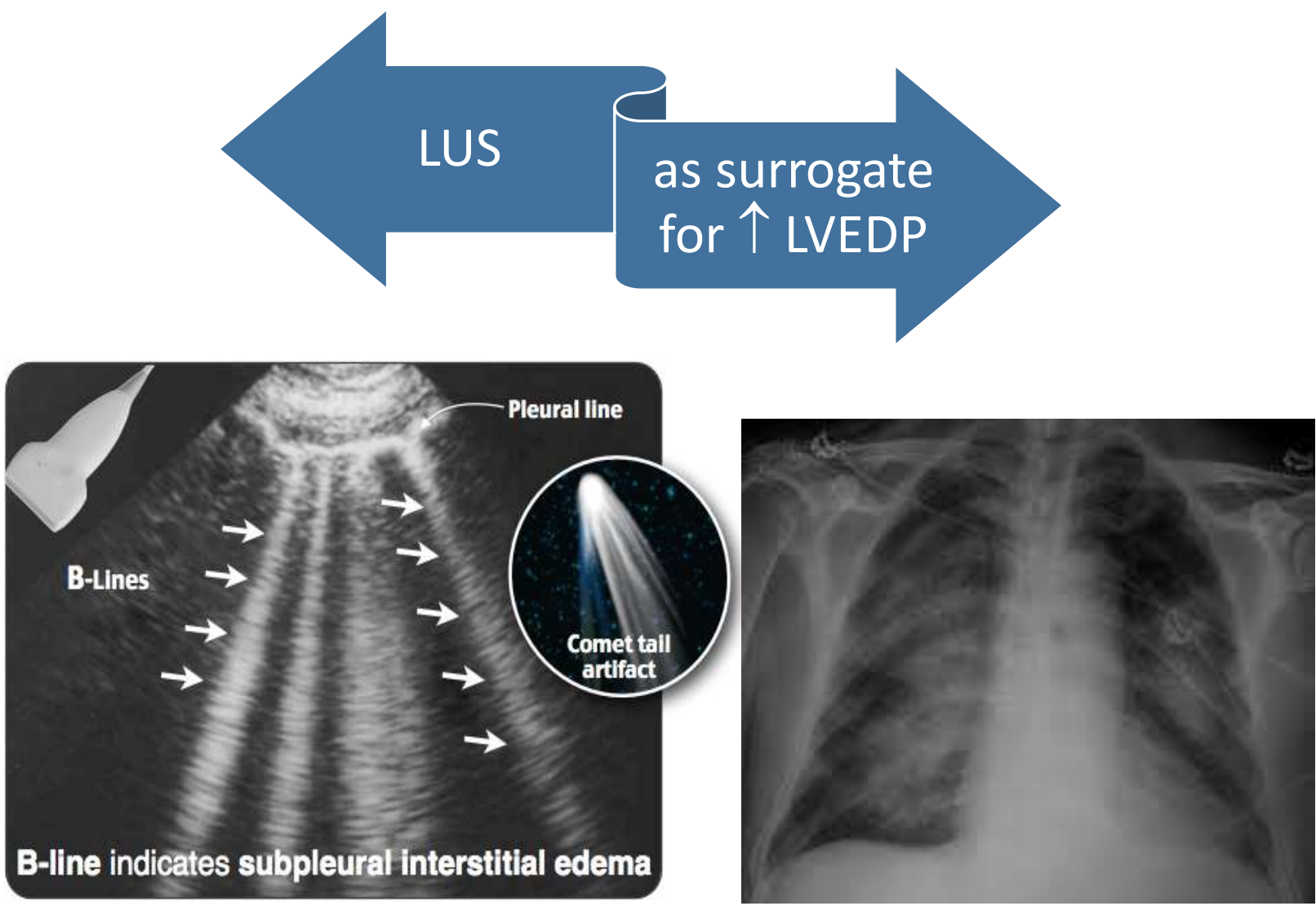


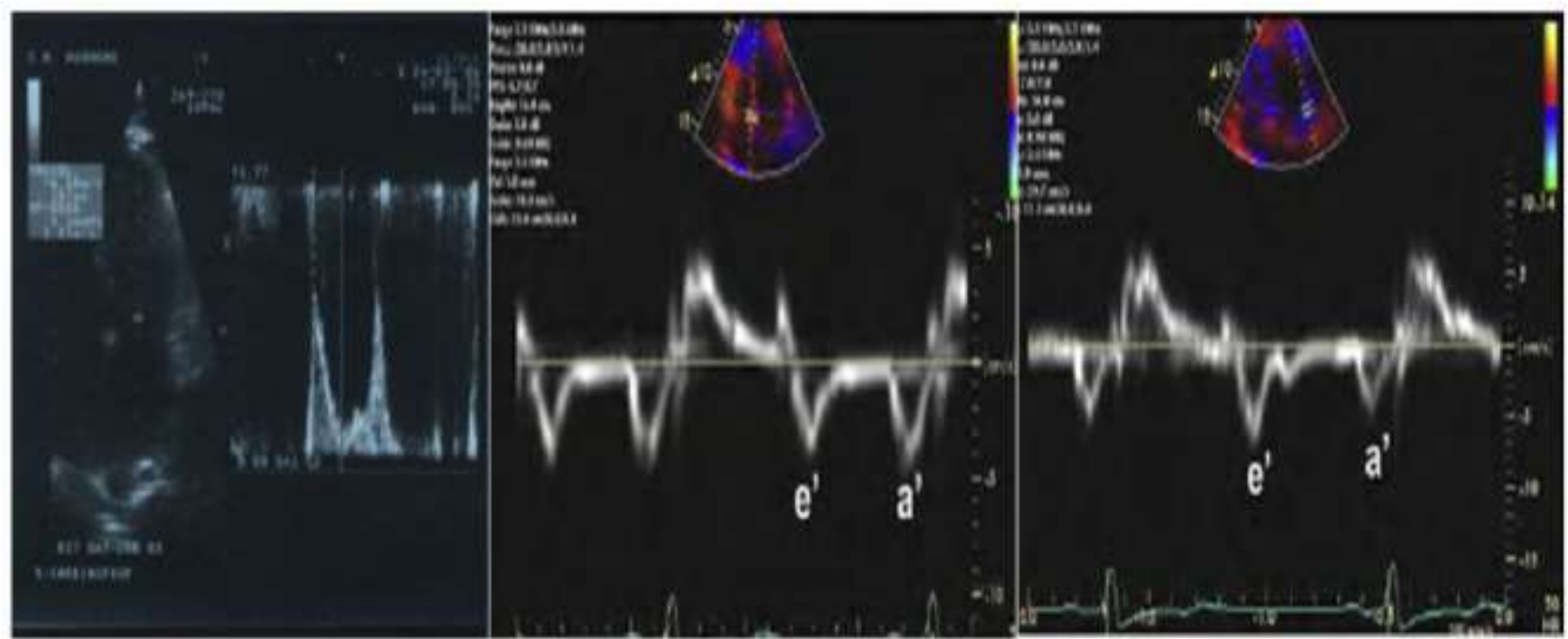

\section{Abstract}

Background: We studied the diagnostic accuracy of B-lines (comet-tail sign) on bedside lung US, NT-proBNP, E/e` on ECHO in differentiation of the causes of acute dyspnea in the emergency setting. Major advantages include bedside availability, no radiation, high feasibility and reproducibility, and cost efficiency.

Methods: Our prospective study was performed at the alazhar university hospital, Cairo, Egypt, between July 2019 and March 2020. All patients underwent lung ultrasound examinations, along with TTE, laboratory testing, including rapid NT-proBNP testing.

Results: The median E/e' levels in patients with B-profile were 18, compared with a median of 7.4 in the subjects with A-profile (P $=<0.0001 \mathrm{CI}=-9.649$ to -7.044$)$. It was found that the sensitivity and the specificity of detecting B-profile on ultrasound is high when E/e' $>15.5$ (95.0\% and 83.0\% consecutively), which concluded the high correlation between finding B profile on U/S chest and elevated left ventricle filling pressure in a patient presenting with picture of suggestive of heart failure

Conclusion: Chest ultrasound can be used as screening test for the evaluation of patients with suspicion of heart failure with excellent sensitivity and good specificity.

Keywords: LUS; B-lines; E/e

\section{Introduction:}

Acute pulmonary edema is a common problem facing emergency department (ED) physicians, and a percentage of these patients are admitted to the coronary care unit (CCU). The diagnosis of acute pulmonary edema remains a challenge for the following reasons: the presentation could be in combination with other diseases, such as chronic obstructive airway disease; and these diseases may have a presentation that is similar to that of acute pulmonary edema [1].

Cardiologists and intensivists commonly assess the heart using echocardiography. To save time, an extended evaluation could be performed using the same probe to complete the evaluation without changing the probe. Chest ultrasound is used to detect subpleural interstitial edema lines (B-lines) and pleural effusion [1]. A B-line is a discrete, laser-like, vertical, hyperechoic image that arises from the pleural line. The B-lines are useful for the diffrential diagnosis of cardiogenic versus non-cardiogenic dyspnea [2].

The assessment of left ventricle diastolic function and filing pressures is of paramount clinical importance to distinguish heart failure (especially heart failure with preserved ejection fraction- (HFPEF)) from other diseases such as pulmonary disease resulting in acute dyspnea. The ratio of E/e' is used to estimate left ventricle filing pressure (LVFP) and its use is recommended by the American Society of Echocardiography (ASE) and
European Society of Cardiology (ESC) for evaluating diastolic dysfunction (DD) and HFpEF $[3,4]$.

The assay for plasma ProBNP is a useful test for the evaluation of patients with dyspnea, and it is particularly useful as a component of the evaluation of a suspected heart failure when the diagnosis is uncertain [5].

Recommended cut-off values for the diagnosis of acute HF using NTproBNP vary substantially. NT-proBNP is renally cleared; therefore, serum levels are affected by age-related declines in renal function. Januzzi et al 2018 showed that age-based NT-proBNP cut-points remain useful for the diagnosis of acute HF and improve diagnostic accuracy compared to any single age-independent cutoff. As rule-in criteria, agestratified cutoff levels of NT-proBNP for diagnosis of HF were as follows: $450 \mathrm{pg} / \mathrm{mL}$ for age $<50$ [ specificity $93.9 \%$ ] , $900 \mathrm{pg} / \mathrm{mL}$ for ages 50-75 [specificity $84.0 \%$ ] $1800 \mathrm{pg} / \mathrm{mL}$ for age $>75$ [ specificity $75.0 \%]$. As a rule-out criterion, NT-proBNP was excellent at ruling out $\mathrm{HF}$ when the level was $<300 \mathrm{pg} / \mathrm{mL}$ [had a sensitivity of $93.9 \%$ and a negative predictive value of $98.0 \%$ ], a useful tool when evaluating patients for causes of acute dyspnea. Unfortunately, this study cannot solve a well-known limitation of NT-proBNP: the "gray zone" of values that can neither rule in or out a diagnosis of HF. Using the cutoffs recommended in this study, the gray zone varies from $300-450 \mathrm{pg} / \mathrm{mL}$ in patients $<50$ years of age to $300-1,800 \mathrm{pg} / \mathrm{mL}$ in patients $>75$ years of 
age. In these cases, other diagnostic tools must be used to diagnose or exclude acute HF. [6]

\section{Aim of the study:}

The aim of our study was to determine the relationship between the B profile on chest ultrasound chest (bilateral comet-tail sign $=$ multiple vertical B lines, referred to as "lung rockets") and E/e' ratio on Spectral tissue Doppler echocardiography in patients presented with the suspicion of acute pulmonary edema.

\section{Patients and methods:}

\section{Study design}

This study was a prospective, observational study in in emergency department (ED) of patients presented with acute dyspnea suspicious of acute pulmonary oedema

\section{Study Population and setting:}

This study was include 120 patients presented with acute dyspnea in Alazhar University hospital ED and CCU

Enrollment or Eligibility criteria:

Patients were selected according to the following:

- Inclusion Criteria : Patients were included if they were:

$\circ \quad>18$ years old and

- had acute dyspnea (defined as either the sudden onset of dyspnea without history of chronic dyspnea or an increase in the severity of chronic dyspnea), and

○ if the treating ED physician's clinical suspects that acute pulmonary edema and left ventricular failure was part of the diffrential diagnosis after the history and physical examination and before any testing was completed or a serum NT-ProBNP was ordered in the ED.

- $\quad$ Exclusion Criteria : We excluded ;

- Patients did not give their consent to participate in the study

- Patients with Lung ultrasound profile pattern other than A \& B,

- Patients with known chest disease as interstitial lung disease, pneumonia, COPD and Asthma.

- Patients with mitral stenosis (because of significant differences in LVEDP compared to other heart disease, so this decreasing the risk of error in filling pressure estimation using LVEDP).

\section{Methods}

All patients will be subjected to the followings:-

\section{[1] Ethical considerations including Written Informed} consent about the type of the study

The study protocol was approved by our local ethics committee.

[2] History taking and physical examination ( Baseline demographic and clinical data )

- $\quad$ Age and Gender

- Cardiovascular risk factors :
- Systemic hypertension was defined as a systolic blood pressure greater than or equal to $140 \mathrm{mmHg}$ and/or a diastolic pressure greater than or equal to 90 $\mathrm{mmHg}$ and/or the use of antihypertensive medication. [7]

○ Diabetes mellitus was Defined by current use of hypoglycemic medications or elevated fasting plasma glucose $\geq 126 \mathrm{mg} / \mathrm{dl}$ or 2 -h post-load plasma glucose $\geq 200 \mathrm{mg} / \mathrm{dl}$ [8]

○ History of ischemic heart disease

$\circ$ History of smoking (Smokers were defined as those with a current or recent history of smoking within the past 1 year.)

- History of dyslipidaemia (Hyperlipidemia was defined by treatment with a lipid-lowering agent.)

- Clinical evaluation

$\circ$ Evaluation of SOB,

○ Right heart failure clinical signs [ e.g. Elevated JVP]

- Left heart failure clinical signs [ e.g. Rales, S3 Gallop]

\section{[3] NT- Pro BNP}

- $\quad$ N-terminal Pro-Brain Natriuretic Peptide (NT-ProBNP) testing was performed within routine care.

- $\quad$ The NT ProBNP level was considered positive at the threshold limit in relation to age. For age $<50$, the threshold limit for being positive was $450 \mathrm{pg} / \mathrm{mL}$, for age 50 to 75 , the level was $900 \mathrm{pg} / \mathrm{mL}$, and for age $>75$, the level was $1800 \mathrm{pg} / \mathrm{mL}$. A level below $300 \mathrm{pg} / \mathrm{mL}$ excludes a diagnosis of heart failure with a negative predictive value of $80 \%$ [6,9].

\section{[4] Thoracic Ultrasound}

Protocol:

- $\quad$ Each patient underwent an 8-zone thoracic ultrasound.

- Ultrasound scans were performed by a physician trained in the techniques of chest ultrasound and echocardiography. The physician was blinded to the E/e' and NT-ProBNP results.

- Ultrasound was performed using portable echocardiography using a Vivid S7 ultrasound system (General Electric Healthcare, Horten, Norway) in the echocardiography preset.

- The exams consisted of bilateral scanning of the anterior and lateral chest wall and were performed with the patients in the supine or near-to-supine position. The correct scan was intercostal with the maximum extension of the visible pleural line. The chest wall was divided into 8 areas, and scans for each area were obtained. The areas included two anterior and two lateral regions per side. The anterior chest wall was delineated from the sternum to the anterior axillary line and was subdivided into upper and lower halves (approximately from the clavicle to the second-third intercostal spaces and from the third intercostal space to the diaphragm). The lateral zone was delineated from the anterior to the posterior axillary line and was subdivided into upper and basal halves. The probe was placed in a cephalic orientation, and the pleural line was placed in the middle of the image by adjusting the depth settings [10]. 


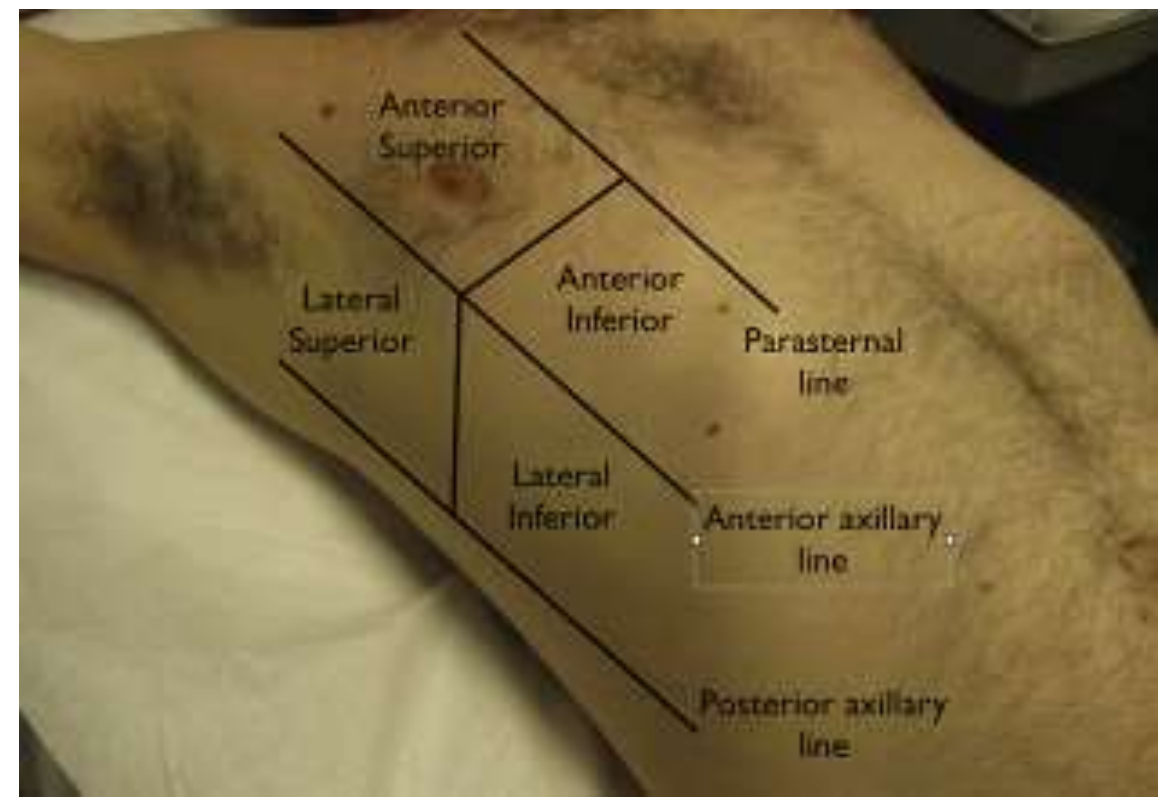

Figure 1: 8-zone thoracic ultrasound.

A positive zone is defined by $\geq 3$ B-lines in the same zone that can be seen at any moment during a respiratory cycle. Adapted from John J. Eicken, et al.2013 [11]

\section{Measurements:}

- The two primary findings on thoracic ultrasound are A-lines and B-lines. A B-line is a comet-tail artifact that arises from the pleural line and moves in concert with lung-sliding. It is long, well-defined, laser-like, and hyperechoic and it erases A-lines [10]. The updated definition of B-line requires three constant criteria (comet tail arising from pleural line and moving with lung sliding) and four quite constant criteria (long, welldefined, hyperechoic and erasing A-line) [2]. An A-line is the repetition of the pleural line, and it is an approximately horizontal hyperechoic line parallel to the pleural line [10]. Two important profiles are detected, as follows: The A-profile (Figure 2) associates anterior lung sliding with A-lines, and the B-profile (Figure 1) is defined by the presence of three or more B-lines in a longitudinal plane between two ribs per scan area, diffuse $\mathrm{B}$ lines in more than one scan per side, and the presence of B lines in both sides associates with anterior lung sliding [3].

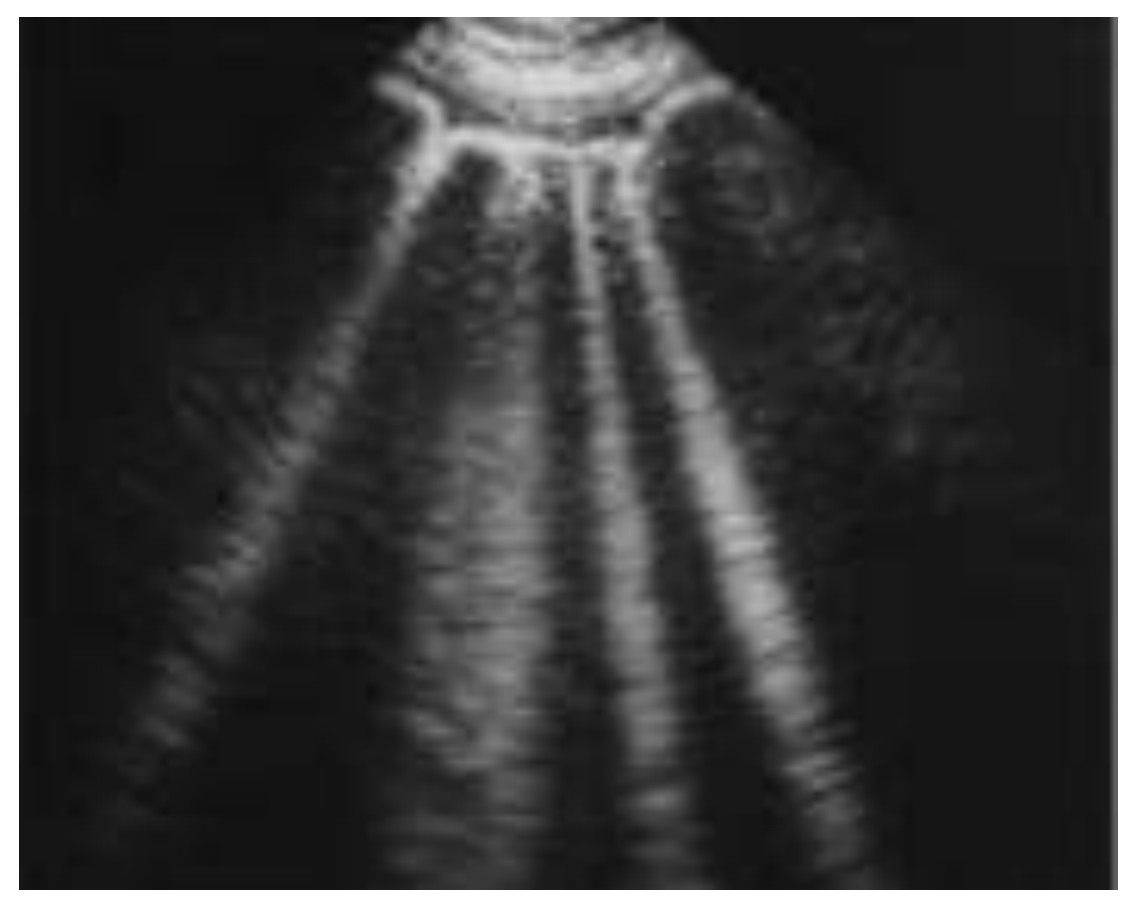

Figure 2a: Multiple B-lines (vertical artifact) in one intercostal space in Patients with pulmonary edema. 
B lines are hyperechoic (white), vertical lines that originate from the pleural line. The appear as "comet tails" and move with lung sliding during inspiration and expiration.

[From Lichtenstein DA et al. The Comet-tail artifact: An Ultrasound Sign of Alevolar-Interstitial Syndrome. Am J Respir Crit Care Med 1997; 156: 1640-1646] [12].

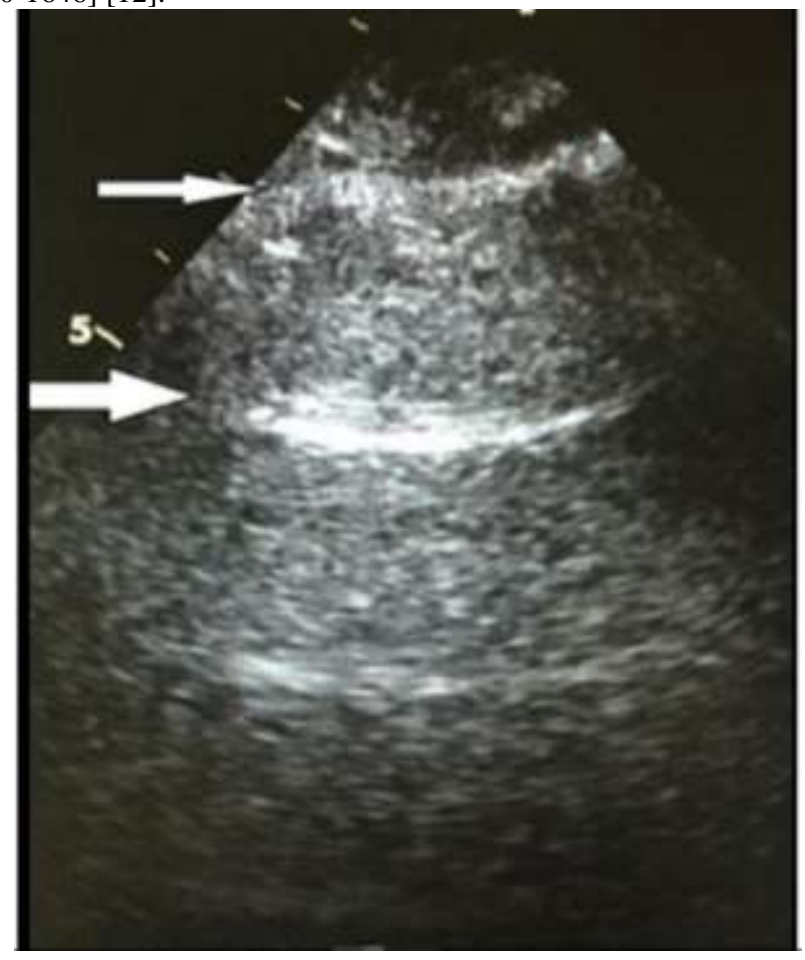

Figure 2 b: A lines. Thin arrow-Pleural line Thick arrow-A line: a horizontal artifact. Adapted From Raheja R, Brahmavar M, Joshi D, et al. (July 25, 2019) Application of Lung Ultrasound in Critical Care Setting: A Review. Cureus 11(7): e5233. doi:10.7759/cureus.5233 [13]

\section{[5] Echocardiography:}

- Echocardiography is the mainstay of the non-invasive evaluation and quantitation of diastolic function [3, 4]. All patients was examined in the left lateral position. All measurement were assessed as recommended by the American Society of Echocardiography (ASE) and European Society of Cardiology (ESC). The analysis was performed offline and blinded to hemodynamic data at the time of analysis. All reported echocardiographic measurements were averaged from 3 consecutive cycles.

- Left ventricular ejection fraction (LVEF) was measured by biplane Simpson's method, and LVEF $\geq 50 \%$ was considered to constitute a preserved ejection fraction [14].

- Mitral inflow velocities was recorded by placing sample volume at the tips of the Mitral valve taken from apical fourchamber view by using pulsed wave Doppler to assess the transmitral peak early diastolic velocity $(\mathrm{E})$, peak late diastolic velocity (A), E/A ratio and $\mathrm{E}$ wave deceleration time (DT) .

- Myocardial stiffness and relaxation abnormalities in diastolic dysfunction (DD) result in elevated left ventricular filing pressure(LVFP) that is indirectly evaluated with echocardiography [3,4]. Early mitral annular velocity (e') obtained with the use of tissue Doppler imaging provides an assessment of LV myocardial relaxation. In conjunction with mitral peak early filing velocity $\mathrm{E}$, the ratio of E/e' is used to estimate LVFP and its use is recommended by the American Society of Echocardiography (ASE) and European Society of Cardiology (ESC) for evaluating diastolic dysfunction (DD)/ heart failure with preserved ejection fraction $(\mathrm{HFpEF})$ [ 3,4 ] (Figure 3 ). E/e' lateral $>12$, E/e' mean $>13$, or E/e' septal $>15$ indicates elevated LVFP, whereas $\mathrm{E} / \mathrm{e}^{\prime}<8$ (any location) indicated normal LVFP [3 ]. When E/e' falls into the intermediate zone $\left(8<\mathrm{E} / \mathrm{e}^{\prime}<12-15\right)$, lung ultrasonography was incorporated into the study to estimate left atrial pressure (LAP), which is considered positive when US chest shows B profile and elevated Pro BNP $[4,15,16]$.

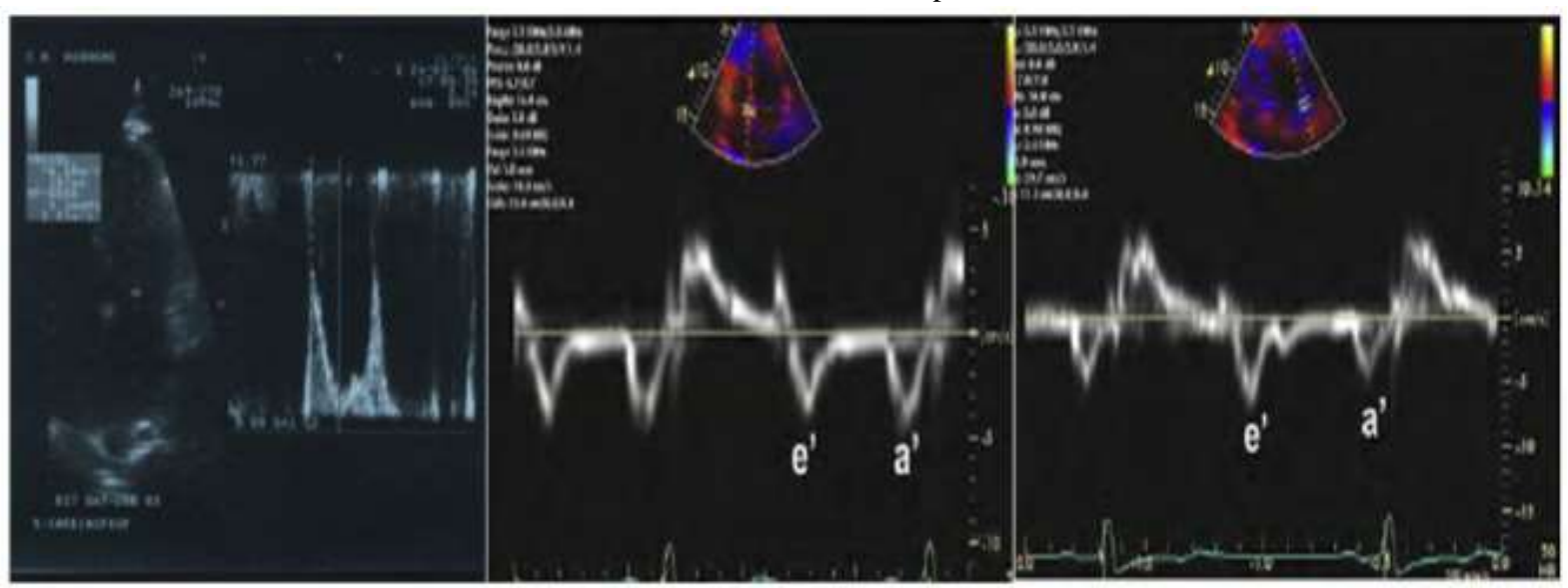

Figure 3: Septal (middle) and lateral (right) tissue Doppler early (e') and late (a') diastolic velocities are markedly reduced with Average Ele' ratio is $>15$, consistent with elevated LV end diastolic pressure

- $\quad$ These velocities are recorded from the apical four-chamber view by placing a $5-\mathrm{mm}$ to $6-\mathrm{mm}$ sample volume over the lateral or medial portion of the mitral annulus to cover the longitudinal excursion of the mitral annulus in both systole and diastole. The velocity scale is set at about $20 \mathrm{~cm} / \mathrm{sec}$ above and below the zero-velocity baseline; the angulation between the ultrasound beam and the plane of cardiac motion was placed to be minimal. The recommendation for spectral recordings is a sweep speed of 50 to $100 \mathrm{~mm} / \mathrm{sec}$ at end expiration, and measurements are averaged for at least three consecutive cardiac cycles [5]. 


\section{Statistical Data analysis:}

- Data were coded \& entered using the statistical demo version of the Graph Pad InStat

- Continuous (Quantitative) variables are presented as mean $\pm S D$, and categorical (qualitative) variables as percentages. Categorical variables were compared among groups using the Chi-square test $(\chi 2)$ test, whereas continuous variables were compared with the analysis of variance test [e.g., MannWhitney Test, paired t-test, unpaired t-test].

- The Pearson correlation coefficient: is a measure of the strength of the linear relationship between two variables. It is referred to as Pearson's correlation or simply as the correlation coefficient. Positive correlation indicates that both variables increase or decrease together, whereas negative correlation indicates that as one variable increases, so the other decreases, and vice versa.

- Tests with p-values less than 0.05 were considered to be statistically significant, $\mathrm{P}$ value $<0.001$ were considered statistically Highly significant, $\mathrm{P}$ value $<0.0001$ were considered statistically extremely significant and $\mathrm{P}$ value $>$ 0.05 was considered statistically non significant.

\begin{tabular}{|c|c|c|c|}
\hline \multirow{2}{*}{} & $\begin{array}{c}\text { B-profile } \\
(91)\end{array}$ & $\begin{array}{c}\text { A-profile } \\
(29)\end{array}$ & \multirow{2}{*}{ P-value } \\
\cline { 2 - 3 } & Mean \pm SD & Mean \pm SD & \\
\hline Age & $66.780 \pm 14.434$ & $68.103 \pm 14.130$ & 0.3333 \\
\hline
\end{tabular}

Values present as Mean \pm Std deviation (SD) were analyzed by Unpaired t test. *: Significant.

Table 1a: Age of the patients in relation to ultrasound chest profile

\begin{tabular}{|l|c|c|c|c|}
\hline & $\begin{array}{c}\text { B-profile } \\
(91)\end{array}$ & $\begin{array}{c}\text { A-profile } \\
(29)\end{array}$ & $\begin{array}{c}\text { Total } \\
(120)\end{array}$ & \multirow{2}{*}{ P-value } \\
\cline { 2 - 4 } & $\mathrm{N}(\%)$ & $\mathrm{N}(\%)$ & $\mathrm{N}(\%)$ & \\
\hline Male Sex & $45(38)$ & $11(9)$ & $56(74)$ & 0.3848 \\
\hline DM & $47(51.6)$ & $12(41.4)$ & $59(49.2)$ & 0.4533 \\
\hline HTN & $55(60.4)$ & $16(55.1)$ & $71(59.2)$ & 0.7752 \\
\hline Smoking & $32(35.2)$ & $12(41.4)$ & $44(36.7)$ & 0.7013 \\
\hline Dyslipidemia & $39(42.9)$ & $14(48.3)$ & $53(44.2)$ & 0.7665 \\
\hline Angina & $50(54.9)$ & $13(44.8)$ & $63(52.5)$ & 0.4614 \\
\hline Prior MI & $59(64.8)$ & $1(3.4)$ & $60(50)$ & $<0.0001 *$ \\
\hline Prior CABG & $18(19.8)$ & $0(0.0)$ & $18(15)$ & $0.0215 *$ \\
\hline AF & $25(27.5)$ & $0(0.0)$ & $25(20.8)$ & $0.0036 *$ \\
\hline Elevated JVP & $45(49.5)$ & $2(6.9)$ & $47(39.2)$ & $0.0001 *$ \\
\hline Rales & $49(53.8)$ & $2(6.9)$ & $51(42.5)$ & $<0.0001 *$ \\
\hline S3 Gallop & $58(63.7)$ & $3(10.3)$ & $61(50.8)$ & $<0.0001 *$ \\
\hline
\end{tabular}

Values present as number \& percent were analyzed by Chi-square test. *: Significant.
There was no statistically significant difference in B-\&A-profiles in relation to baseline demographic and risk factors as regard age, sex, diabetes, hypertension, smoking, dyslipidemia, and Angina, whereas B-profiles were more prevalent among patient with prior MI, prior $\mathrm{CABG}$ and $\mathrm{AF}$. Also B-profiles were more prevalent in patient with signs of right- and left-sided heart failure (with P-value $=0.0001$ ).

\section{Echocardiography and Chest ultrasound profiles}

\section{Results:}

One hundred and twenty patients $(\mathrm{M} / \mathrm{F}=56 / 64)$ with Acute dyspnea referred to our ER and CCU, in Alazhar university hospitals were included in this study.

\section{Baseline demographic \& clinical characteristics and Chest} ultrasound profiles

Age: The mean age was 67.1 years, with a range of 41 to 94 years;

Sex: $56(46.7 \%)$ of the subjects were males.

Risk Factors: 59 patients $(49.17 \%)$ were diabetics, 71 patients $(59.167$ $\%$ ) were hypertensives, 43 patient $(35.83 \%)$ were smokers , 53 patients $(44.16 \%)$ had dyslipidemia , 63 patients $(52.5 \%)$ had angina, 60 patients $(50 \%)$ had MI, 18 patient $(15 \%)$ had CABG , 25 patients $(20.83 \%)$ have $\mathrm{AF}$.

Clinical findings: 91 patients $(75.8 \%)$ had B- profile and hemodynamic pulmonary edema. The remaining 29 patients $(\mathbf{2 4 . 2} \%)$ of had A- profile.

\begin{tabular}{|c|c|c|c|}
\hline & High E/e & Normal E/e & Total \\
\hline B-profile & $89(74 \%)$ & $2(2 \%)$ & $91(76 \%)$ \\
\hline A-profile & $9(8 \%)$ & $20(17 \%)$ & $29(24 \%)$ \\
\hline Total & $98(82 \%)$ & $22(18 \%)$ & $120(100 \%)$ \\
\hline \multicolumn{3}{|c|}{ P value is < $0.0001 *$ [considered extremely significant ] } \\
\hline Sensitivity and specificity \\
\hline Variable & Value & $95 \%$ Confidence Interval \\
\hline
\end{tabular}

Tissue Doppler echocardiography (E/e` ratio): 17 patients had normal E/e' ( $<8$ at any location; septal or lateral ), 74 patient had elevated E/e' (at the septal or lateral side of mitral annulus) . The statistical analysis revealed that A-profile was present in all patients with normal E/e'ratio (E/e' of $<8$ at any location). The median of E/e' levels in patients with B-profile was 18, compared with a median of 7.4 in the subjects with A-profile $(\mathrm{P}=<0.0001 \mathrm{CI}=-9.649$ to -7.044$)$

. 


\begin{tabular}{|c|c|c|}
\hline Sensitivity & 0.9082 & 0.8329 to 0.9571 \\
\hline Specificity & 0.9091 & 0.7083 to 0.9888 \\
\hline Positive Predictive Value & 0.9780 & 0.9228 to 0.9973 \\
\hline Negative Predictive Value & 0.6897 & 0.4918 to 0.8473 \\
\hline Likelihood Ratio & 9.990 & \\
\hline
\end{tabular}

Values present as number \& percent were analyzed by Fisher's Exact test. *: Significant

Table 2a: Chest ultrasound profiles based on tissue Doppler echocardiography (E/e' ratio)

\begin{tabular}{|c|c|c|}
\hline & $\mathrm{E} / \mathrm{e}^{\prime}$ in patient with $\mathrm{B}$-profiles & E/e in patient with A-profiles \\
\hline Mean & 18.240 & 9.893 \\
\hline Std deviation (SD): & 2.546 & 4.389 \\
\hline Median: & 18.000 & 7.400 \\
\hline Lower 95\% CI: & 17.708 & 8.224 \\
\hline Upper 95\% CI: & 18.771 & 11.562 \\
\hline $\mathrm{P}$ value & \multicolumn{2}{|c|}{$<0.0001 *$} \\
\hline Calculation details & \multicolumn{2}{|c|}{$\begin{array}{l}\text { Mann-Whitney U-statistic }=163.50 \\
U^{\prime}=2475.5 \\
\text { Sum of ranks in E/e in patients with B profile }=6661.5 \text {. } \\
\text { Sum of ranks in E/e in patients with A profile }=598.50 \text {. }\end{array}$} \\
\hline
\end{tabular}

Values present as medians were analyzed by Mann-Whitney Test. *: Significant.

Table 2b: Chest ultrasound profiles based on tissue Doppler echocardiography (E/e' ratio)

Systolic function (LVEF): The systolic function in the patient with a B-profile was below $50 \%$ in $77 \%$ of the patient and normal in $23 \%$ of the patient. The patient with an A-profile had a systolic function $>55 \%$.

\begin{tabular}{|c|c|c|c|c|}
\hline & LVEF $>50 \%$ & LVEF <50\% & Total & P value \\
\hline B-profile & $21(18 \%)$ & $70(58 \%)$ & $91(76 \%)$ & \multirow{2}{*}{$0.0001 *$} \\
\cline { 1 - 3 } A-profile & $29(24 \%)$ & $0(0 \%)$ & $29(24 \%)$ & \\
\cline { 1 - 3 } Total & $96(42 \%)$ & $24(58 \%)$ & $120(100)$ & \\
\hline
\end{tabular}

Values present as number \& percent were analyzed by Fisher's exact test. *: Significant

Table 3a: Chest ultrasound profiles based on 2D echocardiography (LVEF)

\begin{tabular}{|l|c|c|}
\hline & LVEF in patient with B-profiles & LVEF in patient with A-profiles \\
\hline Mean & 46.714 & 62.633 \\
\hline Std deviation (SD): & 9.248 & 5.372 \\
\hline Median: & \multicolumn{1}{|c|}{45.000} & 62.000 \\
\hline Lower 95\% CI: & \multicolumn{1}{|c|}{44.785} & 60.628 \\
\hline Upper 95\% CI: & \multicolumn{1}{|c|}{$<0.643$} & 64.639 \\
\hline P value & \multicolumn{1}{|c|}{} \\
\hline Calculation details & $\begin{array}{l}\text { Mann-Whitney U-statistic }=262.50 \\
\text { U' }=2467.5 \\
\text { Sum of ranks in LVEF in patients with B profile }=4448.5 . \\
\text { Sum of ranks in LVEF in patients with A profile }=2932.5 .\end{array}$ \\
\hline
\end{tabular}

Values present as medians were analyzed by Mann-Whitney Test. *: Significant

Table 3b: Chest ultrasound profiles based on 2D echocardiography (LVEF)

\section{NT Pro-BNP and Chest ultrasound profiles}

A-profile was present in all patients with NT-ProBNP $<400$ or $<300 \mathrm{pg} / \mathrm{mL}$.

B-profile was present in all patients with NT-ProBNP positive as rule-in HF criterion $(>450 \mathrm{pg} / \mathrm{mL}$ for age $<50,>900 \mathrm{pg} / \mathrm{mL}$ for ages $50-75 \&>$ $1800 \mathrm{pg} / \mathrm{mL}$ for age $>75$ )

\begin{tabular}{|l|l|l|}
\hline & NT-proBNP in patient with B-profiles & NT-proBNP in patient with A-profiles \\
\hline
\end{tabular}




\begin{tabular}{|l|c|c|}
\hline Mean & 1284.3 & 254.48 \\
\hline Std deviation (SD): & 1841.0 & 23.110 \\
\hline Median: & 1040.0 & 226.00 \\
\hline Lower 95\% CI: & \multicolumn{1}{|c|}{100.23} \\
\hline Upper 95\% CI: & \multicolumn{1}{|c|}{282.29} \\
\hline P value & \multicolumn{1}{|c|}{$<0.0001 *$} \\
\hline Calculation details & $\begin{array}{l}\text { Mann-Whitney U-statistic }=20.000 \\
\text { U' = 2619.0 } \\
\text { Sum of ranks in NT-proBNP in patients with B profile }=6805.0 . \\
\text { Sum of ranks in NT-proBNP in patients with A profile }=455.00 .\end{array}$ \\
\hline
\end{tabular}

Values present as medians were analyzed by Mann-Whitney Test. *: Significant

Table 4: Chest ultrasound profiles based on NT Pro-BNP

\section{B-profile Sensitivity and specificity [Receiver-operating characteristics ( ROC) curve]}

Based on the threshold level of NT Pro-BNP of 398 and significant elevated E/e' (>15.5), the sensitivity of detecting B-profile on ultrasound was $95.0 \%$, and the specificity was $83.4 \%$. The positive predictive value of the B-profile was $94.7 \%$, and the negative predictive value was $85.2 \%$.

\begin{tabular}{|c|c|c|c|c|c|c|}
\hline & Cut-off value & Sensitivity & specificity & +PV & -PV & Accuracy \\
\hline NT-proBNP & $>398$ & 93.3 & 96.7 & 98.8 & 82.9 & 0.8993 \\
\hline Mitral E/e` & $>15.5$ & 96.6 & 70.0 & 90.5 & 87.5 & 0.6663 \\
\hline
\end{tabular}

Table 5: Chest ultrasound profiles Sensitivity and specificity
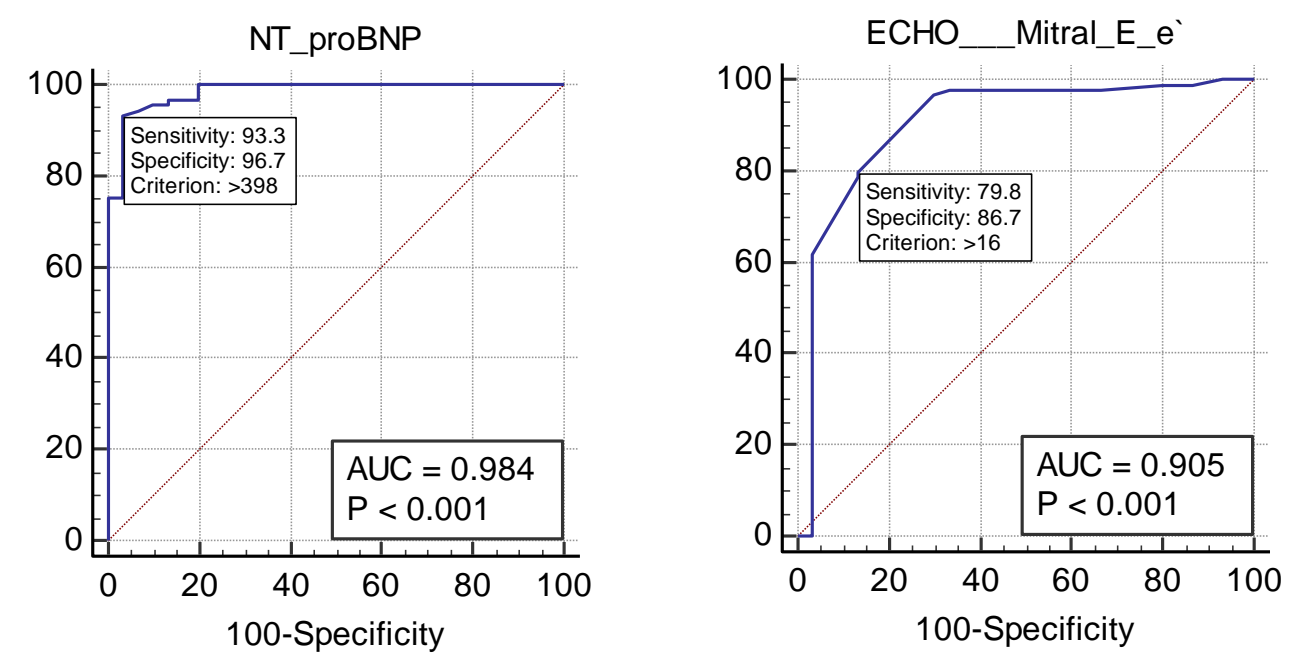

Figure 4: ROC curve for Chest ultrasound profiles Sensitivity and specificity

\section{Discussion:}

Acute dyspnea is one of the most common conditions faced in emergency care settings. Accurate diagnosis and treatment are of primary importance, because misdiagnosis can result in deleterious consequences for patients. Timely differentiation of HF from other causes of acute dyspnea may be difficult. Physical examination, chest radiography, electrocardiography, and standard biological tests often fail to accurately differentiate HF from pulmonary causes of dyspnea $[17,18,19]$.

The clinical diagnosis of acute heart failure (HF) syndromes is challenging in the emergency care setting [20]. Steg PG et al, in the landmark "Breathing not Properly Multinational" study, the Framingham score was reported to be $85 \%$ sensitive and $58 \%$ specific for the clinical diagnosis of congestive HF in a large, unselected patient population presenting with acute dyspnea [21]. Therefore, additional diagnostic methods are required in this clinical setting to accurately establish the diagnosis of acute congestive $\mathrm{HF}$

Rapid NT-proBNP testing, has been validated as a powerful and costeffctive diagnostic marker of congestive HF [22], and is extensively utilized as the first-line diagnostic complement to clinical and radiographic data in in emergency care settings.

Transthoracic lung ultrasound Detection of B-profile is highly sensitive and specific for elevated NT-proBNP, which helps in diagnosing pulmonary edema. Performing chest ultrasound could be part of the echocardiography evaluation in patients with acute dyspnea [23]. 
The reliability of transthoracic lung ultrasound in differentiating acute dyspnea has been confirmed in some previous studies by Lichtenstein et al. [3,12], Cardinale et al [24] and Volpicelli et al. [25]. The study by Lichtenstein et al 1997 was performed in the ICU setting on critically ill patients showed a sensitivity of $93.4 \%$ and a specificity of $93.0 \%$, together with a feasibility of $99 \%$ [12]. The study by Volpicelli et al 2006 was performed in the ED and showed similar results (sensitivity $85.7 \%$, specificity $97.7 \%$, feasibility $98.3 \%$, interobserver variability $4.9 \%$ ) [25]. The comet-tail sign (B lines) has been proposed as a simple, non-timeconsuming sonographic sign of pulmonary congestion and can be obtained at bedside (also with portable echocardiographic equipment) [26]. Agricolla et al. [27] studied the diagnostic accuracy of lung ultrasound in diagnosing intersitial pulmonary edema and found significant positive linear correlations between comet-tail signs and chest radiography, wedge pressure and extravascular lung water quantified by the indicator dilution method. Liteplo et al.[28] reported that lung ultrasound could be used alone or could provide additional predictive power to NT-proBNP in the immediate evaluation of dyspneic patients presenting to the emergency department.

\section{Tissue Doppler echocardiography}

The tissue Doppler (E/e') ratio (a mean of the values obtained at the septum and the lateral wall) is a valuable tool for non-invasive determination of LV diastolic pressures. This ratio is related to pulmonary capillary wedge pressure, so it can be used to identify patients with elevated pulmonary capillary wedge pressure (defined as $>15 \mathrm{mmHg}$ ) accurately [29].

The usefulness of bed-side tissue Doppler echocardiography as well as its incremental role over the clinical judgment and BNP testing in the emergency diagnosis of acute HFpEF in patients hospitalized for acute severe dyspnea is well documented and confirmed; this noninvasive method was found to be accurate, even among patients with inconclusive BNP levels (100-400 pg/ml) or arrhythmia [30,31]. The diagnostic accuracy of E/e' was similar to BNP regardless of LV ejection fraction; furthermore, these 2 methods were able to provide independent diagnostic information, supporting their complementary role in this setting. [32]

Measurement of mitral valve inflow and mitral annular velocity allows the intensivist to identify an elevated or normal left atrial pressure (LAP) in some cases, but may yield an indeterminate result. The ultrasonographer is then required to make a series of echocardiography measurements. Given the time constraints and difficult imaging conditions in the ICU, these are not practical for the frontline intensivist to perform. Instead, lung ultrasonography may be incorporated into the study to estimate LAP. While some data suggest an association between B-line number and right-sided pressures, other did not find a relationship with left-sided pressures as estimated by the PCWP [33]. Agricola et al. studied 20 patients (mean LVEF 64\%) before and after cardiac surgery and did see positive correlations between B-lines on lung ultrasound in 28 chest zones and PCWP $(r=0.48)$ [27]. A study of 72 patients (mean LVEF $41 \%$ ) undergoing stress echocardiography in which PCWP was estimated echocardiographically by tissue Doppler also found positive correlations between estimated PCWP and B-lines $(r=0.69)$ [34]. The discrepancy in results between these studies could be due to diffrent size and type of study populations, the fact that there might be an association between Blines and PCWP, but only in patients with acute decompensated heart failure [33].

In our study the median E/e' levels in patients with B-profile were 18, compared with a median of 7.4 in the subjects with A-profile $(\mathrm{P}=<0.0001$ $C I=-9.649$ to -7.044$)$.

It was found that the sensitivity and the specificity of detecting B-profile on ultrasound is high when E/e' $>15.5$ (95.0\% and $83.0 \%$ consecutively), which concluded the high correlation between finding B profile on U/S chest and elevated left ventricle filing pressure in a patient presenting with picture of suggestive of heart failure .

Also it was noticed that most patients with A profile had normal E/e' ratio.

A study by Zouheir Bitar et al.[1] suggest that the median E/e' levels in patients with B-profie were 20.8, compared with a median of 8.2 in the subjects with A-profile. It was found that the sensitivity and the specificity of detecting B-profile on ultrasound is high when E/e' $>15(95.0 \%$ and $92.0 \%$ consecutively), which concluded the high correlation between finding B profile on U/S chest and elevated left ventricle filing pressure in a patient presenting with picture of suggestive of heart failure .

\section{Limitation}

The limitations of our study include;

- It was a single centre study with a relatively small sample size.

- As an ultrasound evaluation, lung ultrasound (LUS), like any ultrasound evaluation, shares all limitations related to an operator-dependent technique.

- It is also true that since the examination is much simpler than other ultrasound applications (i.e., echocardiography), the interoperator variability is low.

- $\quad$ Results herein should therefore be interpreted with caution and warrant confirmation in larger multicentre studies.

- However, despite these potential measurement caveats, LUS yielded an excellent diagnostic accuracy for elevated LV filling pressure

\section{Conclusion}

\section{From present study we concluded that:}

Chest ultrasound can be used as screening test for the evaluation of patients with suspicion of heart failure with excellent sensitivity and good specificity.The B-line assessment on chest ultrasound is use ful in assessing left-sided filing pressures, so this tool should be considered in a multi-parametric approach of patients with HF. The simplicity of chest ultrasound allows the use of a hand-held device to quickly, easily and adequately evaluate LV filling pressure.

\section{Recommendation}

B-lines are an efficient marker of elevated LVFP. Consequently, they should be more frequently implemented in the assessment of LV diastolic function and LVFP. Their implementation could moreover be extremely easy in routine practice, either prior to or immediately after transthoracic echocardiography, and could be completed within less than 3 minutes.

In addition, because of the portability of recently introduced hand-held devices, LUS could further be easily performed throughout the course of in-hospital management or in the outpatient setting. We do believe, as other authors [35, 36, 37], that LUS is more accurate than lung auscultation $[38,39]$ and should thus be routinely performed in patients with $\mathrm{HF}$ as an extension of clinical examination.

Lung US enables the clinician to more quickly identify and initiate treatment for the potentially life-threatening causes of acute dyspnea without the need for patient transportation to the radiology suite. Additionally, lung US can repeatedly be implemented to assess clinical changes without concern for repeated radiation exposure and is costeffective given its ability to decrease the need for additional radiological and laboratory testing to confirm a suspected diagnosis. 


\section{Aknowledgement}

I would like to express my deepest gratitude to all staff members of cardiology and pulmonology departments, faculty of medicne, Alazhar university, cairo, Egypt .

\section{Abbreviations}

AUROC: Area under the receiver-operating curve

BNP: Brain natriuretic peptide

CHF: Congestive heart failure

CI: Confidence interval

COPD: Chronic obstructive pulmonary disease

CVP: Central venous pressure

HF: Heart failure

LR+: Positive likelihood ratio

LR-: Negative likelihood ratio

NPV: Negative predictive value

NT-proBNP: N-terminal pro-brain natriuretic peptide

PPV: Positive predictive value.

\section{Disclosure Statement}

Dr. Almarghany and Dr Moaz have nothing to disclose.

\section{References:}

1. Maadarani O, Bitar Z, Almeri K (2017) B-Lines on Chest Ultrasound Predicts Elevated Left Ventricular Diastolic Pressures. J Clin Exp Res Cardiol 3(2): 207

2. Lichtenstein DA (2014) Lung ultrasound in the critically ill. Ann Intensive Care 4: 1-12

3. Lichtenstein D, Mezière G (2008) Relevance of lung ultrasound in the diagnosis of acute respiratory failure: the BLUE protocol. Chest 134: 117-25.

4. Copetti R, Soldati G, Copetti P (2008) Chest sonography: a useful tool to diffrentiate acute cardiogenic pulmonary edema from acute respiratory distress syndrome. Cardiovasc Ultrasound 6: 10.1186/1476-7120-6-16

5. Raymond I, Groenning BA, Hildebrandt PR, Nilsson JC, Baumann M, et al. (2003) Th influence of age, sex and other variables on the plasma level of $\mathrm{N}$-terminal pro brain natriuretic peptide in a large sample of the general population. Heart 89 : 745-51.

6. Januzzi JL, Chen-Tournoux AA, Christenson RH, et al. Nterminal pro-b-type natriuretic peptide in the emergency department: The ICON RELOADED study. J Am Coll Cardiol 2018;71:1191-1200.

7. Giuseppe Mancia , Robert Fagard , Krzysztof Narkiewicz , Josep Redon, Alberto Zanchetti , Michael Böhm ,et al . 2013 ESH/ESC Guidelines for the management of arterial hypertension. DOI:

8. Lars Rydén Goldberg RJ, Gore JM, Thompson CA, Gurwitz JH. Recent magnitude of and temporal trends (1994-1997) in the incidence and hospital death rates of cardiogenic shock complicating acute myocardial infarction: the second national registry of myocardial infarction. Am Heart J. 2001;141:65-72.

9. Januzzi JL, van Kimmenade R, Lainchbury J, Bayes-Genis A, Ordonez-Llanos J, et al. (2006) NT-proBNP testing fordiagnosis and short-term prognosis in acute destabilized heart failure:an international pooled analysis of 1256 patients: the International Collaborative of NT-proBNP Study. Eur Heart J 27: 330-7.

10. Volpicelli G, Elbarbary M, Blaivas M, Lichtenstein DA, Mathis $\mathrm{G}$, et al. (2012) International liaison committee on lung ultrasound (ILC-LUS) for international consensus conference on lung ultrasound (ICC-LUS). Intensive Care Med 38: 577-91.

11. John J. Eicken, Michael Billington, Vicki E. Noble, Pulmonary Ultrasound Examination for Edema, Effusion, and Thromboembolism, Global Heart, Volume 8, Issue 4, 2013, Pages 313-321, ISSN 2211-8160,

12. Lichtenstein D, Mezière G, Biderman $P$, Gepner A, Barré O (1997) The comet tail artifact. An ultrasound sign of alveolarinterstitial syndrome. Am J Respir Crit Care Med 156:1640-1646

13. Raheja R, Brahmavar M, Joshi D, et al. (July 25, 2019) Application of Lung Ultrasound in Critical Care Setting: A Review. Cureus 11(7): e5233. doi:10.7759/cureus.5233

14. R.M. Lang, L.P. Badano, V. Mor-Avi, J. Afilalo, A. Armstrong, L. Ernande, F.A. Flachskampf, E. Foster, S.A. Goldstein, T. Kuznetsova, P. Lancellotti, D. Muraru, M.H. Picard, E.R. Rietzschel, L. Rudski, K.T. Spencer, W. Tsang, J.-U. Voigt, Recommendations for Cardiac Chamber Quantification by Echocardiography in Adults: An Update from the American Society of Echocardiography and the European Association of Cardiovascular Imaging, J. Am. Soc. Echocardiogr. 28 (2015) 1 -39.e14. doi:10.1016/j.echo.2014.10.003

15. Nagueh SF, Appleton CP, Gillebert TC, Marino PN, Oh JK, et al. (2009) Recommendations for the evaluation of lef ventricular diastolic function by echocardiography. J Am Soc Echocardiogr 22: 107-33.

16. Levitov AB, Mayo PH, Vastardis L (2015) Echocardiographic Assessment of Lef Ventricular Systolic And Diastolic Function, Critical Care Ultrasonography (2nd edn), McGrawHillGlobal Education Holdings, LLC.

17. Klemen P, Golub M, Grmec S: Combination of quantitative capnometry, N-terminal pro-brain natriuretic peptide, and clinical assessment in differentiating acute heart filure from pulmonary disease as cause of acute dyspnea in prehospital emergency setting: study of diagnostic accuracy. Croat Med J 2009, 50: 133-142. 10.3325/cmj.2009.50.133

18. Michota FA Jr, Amin A: Bridging the gap between evidence and practice in acute decompensated heart failure management. J Hosp Med 2008,3(6 Suppl):S7-S15.

19. Remes J, Miettinen H, Reunanen A, Pyörälä K: Validity of clinical diagnosis of heart failure in primary health care. Eur Heart J 1991, 12: 315-321.

20. Wang CS, Fitz Gerald JM, Schulzer M, Mak E, Ayas NT (2005)Does this dyspneic patient in the emergency department have congestive heart failure? JAMA 294: 1944-56.

21. Steg PG, Joubin L, McCord J, Abraham WT, Hollander JE, et al. (2005) B-type natriuretic peptide and echocardiographic determination of ejection fraction in the diagnosis of congestive heart failure in patients with acute dyspnea. Chest 128: 21-9.

22. Silver MA, Maisel A, Yancy CW, McCullough PA, Burnett JC, et al. (2004) BNP Consensus Panel: A clinical approach for the diagnostic, prognostic,screening, treatment monitoring, and therapeutic roles of natriuretic peptides in cardiovascular diseases. Congest Heart Fail 10: 1-30.

23. Bitar Z, Maadarani O, Almerri K (2015) Sonographic chest Blines anticipate elevated B-type natriuretic peptide level, irrespective of ejection fraction. Ann Intensive Care 5: 10.1186/s13613-015-0100-x.

24. Cardinale L, Volpicelli G, Binello F, Garofalo G, Priola SM, Veltri A, Fava C: Clinical application on lung ultrasound in patients with acute dyspnea:differential diagnosis between cardiogenic and pulmonary causes. Radiol Med 2009, 114: 1053-1064. 10.1007/s11547-009-0451-1 
25. Volpicelli G, Mussa A, Garofalo G, Cardinale L, Casoli G, Perotto F, Fava C, Francisco M: Bedside lung ultrasound in the assessment of alveolar-interstitial syndrome. Am J Emerg Med 2006, 24: 689-696. 10.1016/j.ajem.2006.02.013

26. Jambrik Z, Monti S, Coppola V, Agricola E, Mottola G, Miniati M, Picano E: Usefulness of ultrasound lung comets as a nonradiologic sign of extravascular lung water. Am J Cardiol 2005, 96: 322-323.

27. Agricola E, Bove T, Oppizzi M, Marino G, Zangrillo A, Margonato A, Picano E: "Ultrasound comet-tail images": a marker of pulmonary edema: a marker of pulmonary edema:a comparative study with wedge pressure and extravascular lung water. Chest 2005, 127: 1690-1695. 10.1378/chest.127.5.1690

28. Liteplo AS, Marill KA, Villen T, et al. Emergency thoracic ultrasound in the differentiation of the etiology of shortness of breath (ETUDES): Sonographic b-lines and n-terminal probrain-type natriuretic peptide in diagnosing congestive heart failure. Acad Emerg Med 2009, Mar; 16(3): 201-10.

29. Chirillo F, Brunazzi MC, Barbiero M, Giavarina D, Pasqualini $\mathrm{M}$, et al. (1997) Estimating mean pulmonary wedge pressure in patients with chronic atrial firillation from transthoracic Doppler indexes of mitral and pulmonary venous flow velocity. J Am Coll Cardio 130: 19-26.

30. Arques S, Roux E, Sbragia P, Ambrosi P, Taieb L, et al. (2005)Accuracy of tissue Doppler echocardiography in the emergency diagnosis of decompensated heart failure with preserved left ventricular systolic function. Comparison with Btype natriuretic peptide measurement. Echocardiography 22: 657-64.

31. Arques S, Roux E, Sbragia P, Pieri B, Gelisse R, et al. (2006) Accuracy of tissue Doppler echocardiography in the diagnosis of new-onset congestive heart failure in patients with levels of B-type natriuretic peptide in the mid-range andnormal lef ventricular ejection fraction. Echocardiography 23: 627-34.
32. Dokainish H, Zoghbi WA, Lakkis NM, Quinones MA, Nagueh SF (2004) Comparative accuracy of B-type natriuretic peptide and tissue Doppler echocardiography in the diagnosis of congestive heart failure. Am J Cardiol 93: 1130-5.

33. Platz E, Lattanzi A, Agbo C, Takeuchi M, Resnic FS, et al. (2012) Utility of Lung Ultrasound in Predicting Pulmonary and Cardiac Pressures. Eur J Heart Fail 14: 1276-84.

34. Agricola E, Picano E, Oppizzi M, Pisani M, Meris A, et al. (2006) Assessment of stressinduced pulmonary interstitial edema by chest ultrasound during exercise echocardiography and its correlation with lef ventricular function. J Am Soc Echocardiogr 19: 457-63.

35. S. Coiro, G. Porot, P. Rossignol, G. Ambrosio, E. Carluccio, I. Tritto, O. Huttin, S. Lemoine, N. Sadoul, E. Donal, F. Zannad, N. Girerd, Prognostic value of pulmonary congestion assessed by lung ultrasound imaging during heart failure hospitalisation: A two-centre cohort study, Sci. Rep. 6 (2016). doi:10.1038/srep39426.

36. G. Bedetti, L. Gargani, A. Corbisiero, F. Frassi, E. Poggianti, G. Mottola, Evaluation of ultrasound lung comets by hand-held echocardiography, Cardiovasc. Ultrasound. 4 (2006) 34. doi:10.1186/1476-7120-4-34.

37. E. Agricola, C. Marini, Lung ultrasound predicts decompensation in heart failure outpatients: Another piece to the puzzle but still an incomplete picture, Int. J. Cardiol. 240 (2017) 324-325. doi:10.1016/j.ijcard.2017.04.111.

38. L.W. Stevenson, J.K. Perloff, The limited reliability of physical signs for estimating hemodynamics in chronic heart failure, JAMA. 261 (1989) 884-888.

39. S. Chakko, D. Woska, H. Martinez, E. de Marchena, L. Futterman, K.M. Kessler, R.J. Myerberg, Clinical, radiographic, and hemodynamic correlations in chronic congestive heart failure: conflicting results may lead to inappropriate care, Am. J. Med. 90 (1991) 353-359.
This work is licensed under Creative Commons Attribution 4.0 License

To Submit Your Article Click Here: Submit Manuscript

DOI: $10.31579 / 2641-0419 / 217$

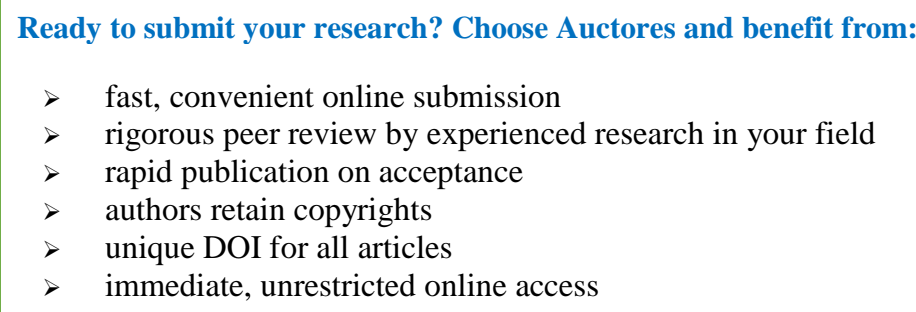

Ready to submit your research? Choose Auctores and benefit from:

$>$ fast, convenient online submission

$>$ rigorous peer review by experienced research in your field

$>$ rapid publication on acceptance

$>$ authors retain copyrights

$>$ unique DOI for all articles

$>$ immediate, unrestricted online access

At Auctores, research is always in progress.

Learn more auctoresonline.org/journals/clinical-cardiology-andcardiovascular-interventions 